\title{
INTERNETSKA MEDIJSKA PREZENTACIJA SIROMAŠTVA SA STANOVIŠTA GRAJSOVOG „PRINCIPA KOOPERATIVNOSTI” I LIČOVOG „PRINCIPA UČTIVOSTI”
}

U radu se predstavljaju rezultati analize teksta i komentara na tekstove o siromaštvu i socijalnoj isključenosti onlajn izdanja B92 sa stanovišta Grajsovog „principa kooperativnosti” i Ličovog „principa učtivosti”.

Jedinica analize je konverzaciona koju čine komunikativni činovi: novinarski tekst i komentari korisnika sajta B92.net.

Cilj je da se uoči kako komuniciraju tekst i komentari kao i komentari međusobno u odnosu na jezičke izbore koji (ne) zadovoljavaju „princip kooperativnosti” i „princip učtivosti”, tačnije njihove kategorije i maksime.

Ključne reči: Internet, princip kooperativnosti, princip učtivosti, maksime, kategorije, medijski tekst, komentari

\section{UVODNA RAZMATRANJA}

Pragmatička lingvistika insistira na društvenom aspektu jezika i efektima koje iskazi imaju. Stoga je pragmatička lingvistika veoma pogodna i za istraživanja medijskih sadržaja i njihovih uticaja na auditorijum.

Pragmatiku interesuje razlika između značenja za govornika i značenja koje mu pridaje sagovornik, odnosno značenja ,iskaza” koji podrazumeva kontekst, a pragmatiku interesuju isključivo značenja u kontekstu (Katz prema Levinson 1983:

$1 \quad$ Ovaj rad pripremljen je u okviru Regionalnog programa podrške istraživanjima u oblasti društvenih istraživanja na Zapadnom Balkanu (RRPP), koji vodi Univerzitet u Frajburgu, uz finansijsku podršku Agencije za razvoj i saradnju Švajcarske (SDC). Mišljenja izneta u ovom radu su mišljenja autora i ne predstavljaju nužno mišljenja SDC ni Univerziteta u Frajburgu. 
20). Nužni uslov analiziranja medijskih sadržaja su konteksti.

Teorija jezičke upotrebe istražuje mehanizme i motivacije koji stoje u osnovi jezičkih izbora i efekat koji ti izbori imaju na nameru da nešto postignu (Verschueren 1995a: 1). Izbor nije obavezno ili-ili odluka, ali korisnik jezika mora da pravi izbore bez obzira na to da li ima na raspolaganju odgovarajuće mogućnosti. Mnoge mogućnosti zavise od kognitivnog, društvenog i kulturnog konteksta.

Feršueren (Verschueren 1995b: 50) navodi tri osnovne osobine jezika posmatrane iz pragmatičke perspektive pomoću kojih se može razumeti „pravljenje izbora". To su: 1) varijabilnost - izbor nije utvrđen jednom za uvek. 2) pregovaranje - pravljenje izbora nije mehaničko, izborom jedne mogućnosti ne isključuju se uvek i potpuno i ostale alternative. 3) prilagodljivost - izbori se prave kroz pregovaranje da bi se zadovoljile osnovne ljudske komunikativne potrebe. Komunikativne potrebe zavise od konteksta i mogu biti sasvim specifične.

Interdisciplinarna istraživanja jezika u upotrebi iz pragmatičke perspektive ogledaju se i u analizi „političkog diskursa” čiji je jedan od istaknutih teoretičara istraživača Teun A. van Dijk (1995). Kritička analiza „diskursa” (van Dijk 1985: 13) zasniva se na interpretaciji jezičkih strategija sagledanih u odnosu na kontekste u kojima se diskurs odvija. Tu se pre svega misli na društveno-politički, kulturni, socijalni, istorijski kontekst.

Kritička analiza diskursa se bavi kritičkim proučavanjem društvenih problema, nejednakosti, dominacije i sličnih fenomena, kao i ulogama koju diskurs, upotreba jezika ili komunikacija imaju u tim situacijama. Zloupotreba moći, dominacija određenih grupa, i posledice koje ista ima na druge grupe ljudi nalaze se u samom središtu ovih studija (Teun van Dijk 2008: 3).

Van Dijk (2008: 9) definiše društvenu moć koristeći termin kontrola. On smatra da društvena moć prvenstveno podrazumeva kontrolu koju jedna grupa ljudi ima nad drugom grupom ljudi i svim njenim članovima. Članovi moćnijih društvenih grupa i institucija, a posebno njihovi predstavnici i vođe, imaju manje ili više ekskluzivan pristup i kontrolu nad jednim ili više vrsta javnog diskursa. Oni koji imaju više kontrole nad značajnijim diskursom, po definiciji imaju više moći. Jedan od najučinkovitijih za distribuciju moći je medijski diskurs. Dekonstrukcijom medijskog diskursa dolazi se do saznanja koje društvene grupe imaju moć u određenoj zajednici i na koji način tu moć praktikuju. 
„Simbolička elita”, koju čine novinari, pisci, umetnici, akademici i ostali koji imaju moć na osnovu „simboličnog kapitala”, takođe kontrolišu proizvodnju diskursa. Oni imaju relativnu slobodu i moć da odlučuju o kojim temama će se pisati u medijima, o žanrovima koji će se objavljivati kao i o stilu i načinu prezentovanja diskursa. Oni takođe odlučuju o temama o kojima se diskutuje u medijima, o osobama o kojima se izveštava u javnosti kao i kako je ta osoba prikazana u medijima. Pripadnici ove „simbolične elite” igraju značajnu ulogu u stvaranju i održavanju struktura pomoću kojih se moć održava u našem savremenom društvu, pošto su u mogućnosti da upravljaju i oblikuju stavove, svest i mišljenja javnosti (van Dijk 2008: 32).

Tema ovog istraživanja je diskurs siromaštva, odnosno dekonstrukcija diskursnih strategija medija kada izveštavaju o siromaštvu u onlajn izdanju medija. Mogućnost direktnog uključivanja u konverzaciju o siromaštvu što omogućava jedino onlajn medij (u ovom slučaju sajt B92) moglo bi da doprinese dekonstruisanju političkih i ekonomskih centara moći, kao i „simboličkih elita”, koji kao izvori informacija mogu da kontrolišu medijski diskurs o siromaštvu i na taj način da dodatno marginalizuju siromašne tranzicijom pogođene građane koji su u raspodeli društvenog proizvoda potpuno potisnuti, pa tako i iz domena odlučivanja na bilo kom nivou.

Onlajn komunikacija istovremeno, mnogo učinkovitije, može da bude kanal kojim će korisnici medija da uđu u dijalog sa izvorima informacija na (ne) tolerantan način. Valja imati u vidu da je u julu 2011. onlajn bilo više od četiri miliona građana Srbije. To znači da su onlajn mediji okupljali veći auditorijum nego bilo koji terestalni pojedinačno posmatrano. Među njima su i mnogobrojni pripadnici siromašnih jer među mladima je čak 50\% od ukupnog broja nezaposlenih u Srbiji². Mladi su najbrojniji korisnici novih medija.

Za ovaj rad su odabrana dva principa koji podržavaju komunikaciju: princip kooperativnosti i princip učtivosti istaknutih teoretičara diskursa Pola Grajsa i Liča. Može se smatrati da u onlajn medijima novinarski tekst i komentari auditorijuma predstavljaju diskurs konverzacije koju čine komunikativni činovi: novinarski tekst i komentari korisnika koji ne moraju nužno biti tolerantni, niti moraju nužno da doprinose održavanju komunikativnog čina.

„U Srbiji je siromaštvo definisano kao višedimenzionalni problem koji, pored

2 http://youth.rs/njuz/ministarstvo-omladine-ne-sme-biti-ukinuto 
nedovoljnih prihoda za zadovoljenje životnih potreba, podrazumeva i nemogućnost zapošljavanja, neodgovarajuće stambene uslove i neadekvatan pristup socijalnoj zaštiti, zdravstvenim, obrazovnim i komunalnim uslugama" (http://www.prsp.gov. rs/staje.jsp).

Broj onih koji žive ispod linije siromaštva u Srbiji je 560.000 i kreće se do gotovo 700.000 građana. Međutim izrazitio je veliki broj onih koji su na samoj granici ali se njihova svakodnevica ni malo ne razlikuje od one koju žive oni ispod linije siromaštva" (Valić Nedeljković 2011).

\section{PRINCIP KOOPERATIVNOSTI}

U najkraćem, Pol Grajs formuliše ,princip kooperativnosti” koji bi trebalo da omogući što uspešniju razmenu informacija i podrži konverzaciju: „Neka vaš doprinos razgovoru bude onakav kakav se traži, u momentu kada se traži prema očekivanoj svrsi i pravcu razgovora u kojem učestvujete" (Grice 1987: 58). Ovaj princip ima četiri kategorije koje opet sadrže maksime i pravila na osnovu kojih se data maksima ostvaruje.

„Kategorije i njihove maksime su sledeće: 1) Kategorija KVANTITETA a/ Vaš doprinos treba da bude onoliko informativan koliko se traži za odredjenu razmenu baš u trenutku kada se ona obavlja. b/ Nemojte da vaš doprinos bude veći no što se traži. 2) Kategorija KVALITETA Pokušajte da vaš doprinos bude istinit to jest: a/ nemojte reći ono što vi verujete da bi moglo biti neistinito. b/ Ne recite ono za šta vam nedostaje odgovarajući dokaz. 3) Kategorija RELACIJE Budite relevantni (ne bežite od teme). 4) Kategorija MODALITETA Budite jasni. a/ Izbegavajte nejasnoće u izražavanju. b/ Izbegavajte dvosmislenosti. c/ Budite kratki. d/ Pazite na red govorenja" (Valić Nedeljković 1997: 32).

Grajs smatra (1987/1967) da su najznačajnije maksime kategorije kvaliteta (nemojte reći ono što vi verujete da bi moglo biti neistinito; ne recite ono za šta vam nedostaje odgovarajući dokaz) i ako su one zadovoljene, tek onda važe ostale. Upravo je to i osnovni zahtev etike medija na kojem se zasniva kvalitetno novinarstvo.

„Sagovornici mogu da izbegnu da se pridržavaju maksima. To čine na nekoliko načina: neprimetno, mogu da aludiraju, ili jasno da kažu da se neće pridržavati maksima ni načela kooperativnosti; mogu biti u sukobu jer ne mogu 
da ispune prvu maksimu kvantiteta, a da ne povrede drugu maksimu kvaliteta; ili jednostavno mogu da se rugaju nekoj maksimi.

Grajs smatra da osoba može reći jedno, a (razgovorom) implicirati sasvim drugo, samo pod tri određena uslova: poštovanjem maksima i načela kooperativnosti; podrazumevanjem da je osoba svesna potrebe postojanja onoga što se razgovorom implicira, čega su svesni i govornik i sagovornik.

Za postojanje konverzacionih implikatura (postupak davanja do znanja ili impliciranja u kazanom nečeg drugog), bez obzira da li su istinite ili lažne, potrebno je i znanje o kontekstu, o temi o kojoj se razgovara kao i druge relevantne informacije (Valić Nedeljković 1997: 33).

\section{„PRINCIP UČTIVOSTI”}

Grajsov ,pprincip kooperativnosti” je nadogradio G. N. Lič (1989/1983 : 132) formulišući ,princip učtivosti” (kod Vučkovića 1995 : 90, „taktičnosti”).

„Postoji 6 maxima UČTIVOSTI 1) Maksima TAKTA (potvrdan i izražajan) a/ minimizirati štetu drugima; b/ maksimizirati korist za druge. 2) Maksima VELIKODUŠNOSTI a/ minimizirati korist za sebe; b/ maksimizirati štetu za sebe. 3) Maksima ODOBRAVANJA (izražajan i potvrdan)a/minimaliziranje omalovažavanja drugog; b/ maksimaliziranje uvažavanja drugog. 4) Maksima PRISTOJNOSTI (i izražajan i potvrdan) a/ minimalizacija uvažavanja sebe; b/ maksimalizacija neuvažavanja sebe. 5) Maksima SAGLASNOSTI (potvrdan) a/ minimalizacija neslaganja izmedju sebe i drugog; b/ maksimalizacija saglasnosti izmedju sebe i drugoga. 6) Maksima SIMPATIJE (potvrdan) a/ minimalizacija antipatije izmedju sebe i drugoga;b/ maksimalizacija simpatije izmedju sebe i drugoga" .

Hijerarhija različitih maksima zavisi ne samo od kulture, konteksta, situacije, uloga, odnosa već i od mnogih drugih faktora.

Grajsov ,princip kooperativnosti”, kao i Ličove maksime imaju ograničeno polje primene. Ne odnose se na sve što je izvan svakodnevnih komunikativnih situacija, na primer na umetničke forme. Međutim, kada je reč o onlajn medijskom diskursu, koji je istovremeno i institucionalna komunikacija (novinarski tekst objavljen $\mathrm{u}$ javnom mediju) i interpersonalna privatna komunikacija (komentari korisnika sajta), najčešće o temama iz svakodnevnog života (u ovom slučaju o 
siromaštvu), namenjenih prosečno obrazovanom auditorijumu (koji čita onlajn medijske sadržaje/ ukupni broj internet korisnika 2011. u Srbiji je $4107000^{3}$ ), provera primene Grajsovog principa kooperativnosti i Ličovih maksima, kao jedan od mogućih načina dekonstrukcije društvene i ekonomske moći odnosno statusa učesnika u ovom tipu komunikacije, predstavlja pravi izazov i ima puno opravdanje.

\section{KORPUS}

Korpus čine tekstovi i komentari objavljeni na Sajtu B92 o siromaštvu i socijalnoj isključenosti ${ }^{4}$. Vremenski okvir za uzorkovanje materijala za analizu obuhvatao je dva važna događaja za ovu temu: Svetski dan hrane i borbe protiv gladi (16.10) i Svetski dan borbe protiv siromaštva (17.10). Na Sajtu B92 16. oktobra objavljeno je 6 tekstova koji se odnose na temu i ukupno 153 komentara. Narednog dana 17. oktobra objavljeno je 10 tekstova i ukupno 271 komentar. U celom korpusu je najmanje bilo komentara na tekst „PIK Zemun u novim problemima” (17.10.2011) bez komentara i najviše po pojedinačnom tekstu „Nikolić: ja sam garant za milijarde” (17.10.2011) 156 komentara.

Izabran je sajt B92 stoga što je jedan od tri najposećenija u Srbiji, a i stoga što objavljuje i preuzete tekstove iz drugih medija tako da se na ovom sajtu mogu pročitati raznovrsni medijski sadržaji i steći predstavu o tome šta se o jednoj temi objavljivalo u relevantnim sredstvima javnog komuniciranja u određenom periodu.

Korpus je šifriran tako što je tekstu data oznaka medija (92), datuma (npr 16. Oktobar ali se koristi samo cifra dana a ne i meseca) i na kraju broj teksta na tom sajtu u tom danu (92-16-5). Komentarima se na šifru teksta dodaje i redni broj komentara na sajtu (92-16-5:1).

\section{Jedinica analize medijskih sadržaja na Internetu}

Za analizu medijskog sadržaja u kontekstu onlajn prezentacije trebalo bi odrediti konverzacijske jedinice analize koje zadovoljavaju najmanje dva uslova:

3 Podatak se množe naći na http://www.hugemedia.rs/blog/2011/07/29/konacnaanaliza-internet-marketing-u-srbiji-i-hrvatskoj/ pregledano 23.05.2012.

4 Rad je nastao na osnovu rezultata naučnoistraživačkog projekta Medijski diskurs o siromaštvu $i$ socijalnoj isključenosti, koji je sproveo Odsek za medijske studije Filozofskog fakulteta u Novom Sadu. Projekat je realizovan u okviru Regionalnog programa podrške istraživanjima u oblasti društvenih istraživanja na Zapadnom Balkanu (RRPP), koji vodi Univerzitet u Friburgu, uz finansijsku podršku Švajcarske agencije za razvoj i saradnju (SDC). Mišljenja izneta u ovom izveštaju su mišljenja autora i ne predstavljaju nužno mišljenja SDC niti Univerziteta u Friburgu. 
(a) odražavaju osnovnu unutrašnju strukturu onlajn teksta sa komentarima; (b) primenljive su u svim onlajn medijskim izdanjima koja omogućavaju postavljanje komentara korisnika (bez obzira na broj učesnika u komentarisanju, broj tema koje se smenjuju u komentarisanju teksta, sajberprostor vremena u kojem se ova interakcija odigrava).

Za konverzacijsku jedinicu analize onlajn medija određeni su:

-komunikativni događaj (određeni, pojedinačni u ovom slučaju novinarski tekst na Sajtu B92 i komentari korisnika sajta) koji se sastoji od dva komunikativna čina;

-komunikativni čin novinarskog teksta i komunikativni čin komentara korisnika (kao redovi saopštavanja informacija autora novinarskog teksta i auditorijuma/korisnika sajta).

Svaki komunikativni događaj odvija se u određenim komunikativnim situacijama koje na njega utiču posredno i neposredno. Čine je mnoge komponente: tip medijskog sajta (radijski sajt, TV sajt, onlajn izdanje novina), sajberprostor vreme (vrlo specifično određivanje prostorne/vremenske jedinice analize), status učesnika (podređeni/nadređeni, ravnopravan), pol, uloge (novinar, korisnik sajta), društvenopolitički kontekst (Srbija kao tranziciona zemlja obremenjena ekonomskom krizom) i kulturni kontekst (markiran i jezikom: sajt na maternjem/analizirani sajt u ovom slučaju, ili na engleskom jeziku), kontekst teme (u ovom slučaju siromaštvo).

\section{ANALIZA \\ PRINCIP KOOPERATIVNOSTI}

Principu kooperativnosti Pola Grajsa definiše racionalno korišćenje komunikacijskih resursa. Suštinski to se očekuje od svakog medijskog teksta. U onlajn dijalogu između medijskog sadržaja i komentara auditorijuma očekuje se kooperativnost koja otvara javni dijalog o temama od opšteg interesa.

Teme iz oblasti siromaštva i socijalne isključenosti su u Srbiji danas od izuzetnog opšteg interesa jer je broj siromašnih i onih koji su na ivici siromaštva u stalnom porastu zbog dugotrajne ekonomske krize kako kod nas tako i u Evropi. Istovremeno rezultati istraživanja iz 2011. na projektu RRPP, koji je prethodio ovome, osnovni zaključak je bio da se mediji ne bave siromašnim osobama već 
statističkim podacima o siromaštvu. Stoga je važno analizirati da li internetski korisnici medijskih sadržaja reaguju na ovakav način istraživanja o siromaštvu; da li to čine na kooperativan način odnosno; da li su ,učtivi”, tačnije tolerantni, u dijalogu sa novinarskim tekstom, ili temom kao takvom, odnosno nekim ko je pre njih komentarisao isti sadržaj.

Novinari su u pregledanim tekstovima zadovoljili princip kooperativnosti Pola Grajsa i njegove kategorije kvantiteta, kvaliteta, relacije i modaliteta. To se može i pretpostaviti jer je u kategorijama sažeta osnova novinarskog profesionalizma.

\section{Kategorija kvantiteta}

a/ Vaš doprinos treba da bude onoliko informativan koliko se traži za određenu razmenu baš u trenutku kada se ona obavlja. b/ Nemojte da vaš doprinos bude veći no što se traži.

Tekstovi su zadovoljili ovaj kriterijum bili su između 211 reči (Stranke nude samo obećanja, Izvor: Večernje novosti) do 1102 reči (Srpski i radnik u EU - kome je teže, Izvor: Novosti).

Sa komentarima je takođe odnos sličan. Od veoma kratkih i šturih koji su red govorenja, konverzaciona jedinica analize, ali nisu informativni

Primer $1^{5}:$ 92-17-10:112

hahahahahahahahahaheheh eheheehhahahaeheahehaehae eeahheahehaheahahehaehahehaehahe haeheaheaheah ehahedhaehea heah HA :(

(treci, 17. oktobar 2011 20:58)

...do ozbiljnih analiza teme teksta (470 reči 92-17-8:10 $\quad$ 17. Oktobar 2011).

Stalni internet korisnici znaju i iz sopstvenog iskustva da se zadržavanje na stranici meri sekundama da dugi komentari neće imati efekta jer ih niko neće čitati.

\section{Kategorija kvaliteta}

Pokušajte da vaš doprinos bude istinit to jest: a/ nemojte reći ono što vi verujete da bi moglo biti neistinito. b/ Ne recite ono za šta vam nedostaje odgovarajući dokaz.

Novinarski tekstovi su poštovali ovu kategoriju. Najpre je administrator sajta za sve tekstove naveo izvor i vreme kada su postavljeni, označio je takođe i poziciju teksta, ali ne i ime autora teksta.

\section{Primer 2:}

5 Svi primeri su navedeni u obliku u kojem su objavljeni na Internetu. Nije unesna ni pravopisna, niti ikakva druga intervencija u tekst. 
Srbija | nedelja 16.10.2011 | 14:29

Stipendije i posao zadržavaju mlade

Izvor: Blic

U svim novinarskim tekstovima su navedeni izvori informacija i direktni citati su jasno označeni sa punim imenom i prezimenom, kao i navedenim svojstvom osobe koja je citirana. Uočeno je da su to uglavnom javne ličnosti iz domena politike i ekonomije, najčešće pozicionirani u državnoj administraciji. Znači o temama siromaštva i socijalne isključenosti u ovom korpusu su govorili oni koji se bave javnim politikama (zapošljavanje, nove investicije, programi političkih stranaka, odnos poslodavaca i radnika), a sasvim sporadično oni koji su direktno pogođeni ekonomskom krizom.

Za razliku od teksta u kojem se citiraju donosioci odluka, a time i nosioci moći u društvu, u komentarima se javljaju osobe pogođene siromaštvom i socijalnom isključenosti. Oni iz sopstvenog iskustva, bez citiranja autoriteta, odnosno navođenja ikakvog izvora za podatke ako ih daju, iznose najčešće suprotne informacije u odnosu na tekst. Komentatori dosledno nisu poštovali ovu kategoriju.

\section{Primer 3}

Novinarski tekst:

B92-16-4 Stipendije i posao zadržavaju mlade, Izvor: Blic

Subotica, Jagodina, Inđija, Šabac i Svilajnac - opštine su u Srbiji koje su značajno smanjile trend iseljavanja u veće gradove radi traženja posla.

Od 2002. do 2010. Subotica, Jagodina i Inđija imale su priliv stanovnika, dok su Šabac, Pirot i Zrenjanin beležili odliv“, kaže ekonomista Miroslav Zdravković.

Komentari:

92-16-4:7

IGB Automotive iz Indjije je zaposlio u 2010. 500 radnika a otislo je 450 radnika zbog zdravstvenih problema sa plucima. Da dopunimo informaciju.

(Miljko, 16. oktobar 2011 15:43)

Preporučujem (+23) Ne preporučujem (0)

Komentatori su potpisani imenom, ili pseudonimom, veoma retko punim imenom i prezimenom. $U$ ovom korpusu je samo jedan takav primer. 
Primer 4

92-17-10:52

Ovo je sramota! *** A sutra će Vučić da pegla situaciju.

(Nikola Vidović, 17. oktobar 2011 19:11)

Preporučujem (+113) Ne preporučujem (-5)

Autorstvo/potpis pod komentar kao izvor informacija nije relevantan podatak pošto se ne zna ko je tačno autor i da li ima kredibilitet za informacije koje pruža virtuelnoj javnosti.

Kategorija relacije

Budite relevantni (ne bežite od teme).

Ova kategorija Pola Grajsa je potpuno zadovoljena u svim tekstovima i novinarskim i tekstovima komentara. Komentari u ovom korpusu su se najčešće direktno odnosili na temu teksta (Primer 5); zatim na prethodni komentar o temi teksta sa naznakom na koga referiraju (Primer 6), na osobu koja je citirana u tekstu (Primer 7) i na kraju postoje i primeri šaljivog referiranja koje se mora kontekstualno „ćitati” da bi bili razumljivi (Primer 8). Tačnije Grajsovo „podrazumevajuće razumevanje” je neophodno da bi se dekodirale ovakve poruke (prema Valić Nedeljković 1997 : 14).

Primer 5

92-16-3:20

EU ima mnogo bolje sisteme javnog informisanja i slobode govora tako da svaki veci problem ce se pojaviti u vestima dok u Srbiji veliki broj nepravilnosti i teskoca se gura pod tepih kako bi statistika izgledala bolje. Treba imati takve stvari u vidu kada se porede uslovi zivota.

(Milos, 16. oktobar 2011 20:52)

Primer 6

92-16-3:15

(a) Poso

Hvala na iscrpnoj analizi. 
92-16-3:18

(a) Zika:

To zaista nije istina. Bar sto se Svedske tice. Zivim u istoj i mogu reci da su moja primanja ista kao i primanja mojih koleginica. To isto vazi i za moju zenu kada je rec o njenom poslu.

Kako je u Svajcarskoj zaista ne znam, ali ovde se prava radnika veoma postuju.

(Jovan, 16. oktobar 2011 19:58)

\section{Primer 7}

Novinarski tekst: Srbija neće imati para za penzije, Izvor: Press, 92-16-5

Dragoljub Rajić iz Udruženja poslodavaca Srbije kaže da je tačno da vlasnici manjih preduzeća pribegavaju prijavljivanju minimalne zarade, ali ističe da su državne firme najveći dužnici za plaćanje doprinosa. (...)Imajući to u vidu, jasno je zašto je zaključno sa junom ove godine dug domaćih kompanija prema PIO fondu narastao na čak 233,2 milijarde dinara. Prema podacima Poreske uprave, glavnica duga iznosi oko 104,5 milijardi dinara, dok ostatak od 128,6 milijardi čine kamate. Ovakva situacija zabrinula je članove UO PIO fonda, jer svake godine iz budžeta se izdvaja sve više novca.

Komentar. 92-16-5:93

Pitajte g-dina Rajića, ako je PIO Fond u tolikom minusu, zašto Unija poslodavaca Srbije ne vrati 100 MILIONA DINARA (ovo je tačna cifra, ne zaokružena) koje je dobila na ima „projekata“ od PIO Fonda! (Radnik PIO, 16. oktobar 2011 23:09)

Primer 8

92-16-6:3

Ma kako je to moguce? U bratskoj Rusiji(Ceceniji)? Ma nemoguce..tamo tece med i mleko i cokolade rastu na drvecu. Pitajte ove nase rusofile..i onog ambasadora. (ZokiNS, 16. oktobar 2011 21:01)

Kategorija modaliteta 
Ova je poslednja na spisku Pola Grajsa i imperativno upućuje sagovornike „Budite jasni”:

a/ izbegavajte nejasnoće u izražavanju i b/ izbegavajte dvosmislenosti.

Novinari su se držali i ove potkategorije jer predstavlja osnovni urednički zahtev, što se za komentatore ne može tvrditi. Njima je osnovno da pokažu svoj stav prema novinarskom tekstu i to na što atraktivniji način, tako da jasnoća nije primarna. Često se namerno pogrešno upotrebljava pravopis ili znaci interpunkcije što sve može da dovede do šuma u komunikaciji. Na dvosmislenosti se zasniva evazivno novinarstvo. U ovom korpusu, iako su se na sajtu B92 našli i tekstovi iz tabloidne štampe, nije uočena jezička strategija koja bi se mogla svrstati u dvosmislenost. Dvosmislenost je imanentna političkom diskursu (Primer 9).

\section{Primer 9}

Novinarski tekst: Stranke nude samo realna obećanja, Izvor: Večernje novosti, 92-16-1

Jelena Trivan, potpredsednica DS, kaže da će ova stranka u predizbornoj kampanji kao mere za poboljšanje života predložiti ono što je ostvarivo, za šta ima novca i što je moguće izvesti sopstvenim snagama.

"Nećemo pričati bajke o milijardama evra koje ćemo doneti u zemlju kao što to čine neke druge partije, koje se utrkuju u obmanjivanju ljudi”, kaže Trivanova.

Komentari su bili dvosmisleni.

Primer 10

92-16-1:12

Da li je ova vest preuzeta sa njuz.net? :)

(klingon, 17. oktobar 2011 08:42)

Preporučujem $(+12)$ Ne preporučujem (0)

92-16-1:11

Ali ja bas hocu da mi neko obecava ,leb za dinar...

(Inglorious Basterd, 17. oktobar 2011 00:08) 
c/ Budite kratki.

Ovo je kao što je već objašnjeno u kategoriji kvantiteta bilo sasvim sprovedeno i u novinarskim i u tekstovima komentara. Valja napomenuti još i to da je dužina teksta suštinski takođe posledica uredničke moći. Urednici utvrđuju sa novinarima temu, žanr i obim teksta stoga nije slučajno što je, na primer, u oktobru predizbornim obećanjima (pet meseci pre raspisivanja izbora) dato samo 278 reči, a direktno su citirani predstavnici isključivo partija od kojih se očekuju da najviše ulože u kampanju i budu izborni dobitnici SNS, DS, URS i SDPS.

d/ Pazite na red govorenja.

Ova potkategorija se najdirektnije odnosi na govornu komunikaciju, tako da za internetsko komuniciranje pisanom rečju nije bila relevantna. U odnosu na performanse medija u formi koja je analizirana nije primenljiva.

\section{PRINCIP UČTIVOSTI}

G.N. Ličov princip učtivosti i njegovih 6 maksimuma pokazali su se malo učinkovitim u analizi teksta i komentara na Sajtu B92. Teorijska pretpostavka je bila da je odnos novinarskog teksta i komentara u suštini konverzacija između autora teksta i autora komentara koji bi trebalo da uđu u javnu raspravu o temi i bude u određenom stepenu (ne)tolerantna.

Međutim, analiza je pokazala da se novinari nisu oglašavali komentarom na komentar internet korisnika o njihovom tekstu, što jeste, na primer, bio slučaj u analizi polemike o teizmu i ateizmu koja se vodila na onlajn stranicama dnevnog lista Danas ${ }^{6}$. Takođe i sami komentatori su veoma retko direktno referirali na nečiji prethodni komentar (Primer 11) tako da bi se mogao tekst sameriti sa Ličovim maksimama.

\section{Primer 11}

$6 \quad$ Dubravka Valić Nedeljković Analiza diskursa polemike o religioznosti i sekularizmu/teizmu $i$ ateizmu u dnevnom listu Danas, rad prezentovan na međunarodnoj konferenciji Mediji, religija i nasilje u postkonfliktnom društvu, Beograd, 18 i 19. maj 2012. 
92-16-3:15

@ Kejt

Ovo pitanje sam postavio jer mislim da većina radnika nije toliko disciplinovana da ispuni sve ono što sam naveo u mom pitanju.

(Zanatlija, 16. oktobar 2011 16:59)

U kodnom listu (saglasnost sa maksimama beležena sa + , nesaglasnost sa -, a neutralnost, odnosno nepostojanje odnosa sa 0). Za novinarske tekstove se najčešće mogla navesti saglasnost sa svih šest maksima, što se moglo i očekivati jer se od novinara traži neutralnost i distanca u odnosu na temu, subjekt i objekt teksta. Podsećamo da ni jedan novinski intervju nije u ovom korpusu zabeležen, a u intervjuu bi Ličove maksime bile veoma primenljive ${ }^{7}$.

U komentarima korisnika sajta beleži se nesaglasnost sa većinom maksimama, i u visokom broju neutralnost u maksimama Velikodušnosti i Pristojnosti pošto autori komentara najčešće pišu o drugom, odnosno o temi, a ne o odnosu sebe prema drugom, sebe prema temi.

$\mathrm{Na}$ implicitnom nivou dakako jeste lična sudbina osnov za komentar, te bi se moglo interpretirati da je komentator u ličnom „dijalogu“ sa temom, odnosno subjektima novinskog teksta, što je u analizi i korišćeno kao metodološka alatka.

\section{ZAKLJUČAK}

Testiranje dva veoma poznata principa kooperativnosti i $u$ čtivosti koji bi trebalo da doprinesu tolerantnijoj interakciji u komunikaciji u internetskom sajber prostorvremenu pokazalo se veoma učinkovitim, iako su autori Pol Grajs i G. N. Lič principe definisali decenijama pre nastanka Interneta.

Analizom je utvrđeno da su se u ovom korpusu kategorije i njihove maksime Grajsovog principa kooperativnosti pokazale veoma primenljivim te da se mogu koristiti u analizama medijskih sadržaja u onlajn kontekstu. Istovremeno iako je u posmatranom korpusu reč o interakciji na Internetu, Ličov princip učtivosti se nije

$7 \quad$ Dubravka Valić Nedeljković Pragmatičke osobine intervjua ostvarenih na radiju, doktorska teza odbranjena na Filozofskom fakultetu, Univerzitet u Novom Sadu, 1997. 
pokazao primenljivim na dati korpus, jer je sajber interaktivnost ipak samo medijem posredovana pisana komunikacija, te tako izostaje najdirektniji dijalog licem u lice.

Tema analiziranog korpusa je bila siromaštvo i ova analiza je potvrdila rezultate prethodnog istraživanja (Valić Nedeljković, ur. 2011) da se mediji ne bave siromašnim osobama, već statističkim podacima o siromaštvu i da o ovom društvenom, veoma izraženom, problemu govore u medijima oni koji imaju moć donošenja odluka i javnih politika. Šansu da svoje stavove iznesu nemaju oni koji jesu pripadnici grupe, koja je u problemu, posebno mladi, obrazovani, nezaposleni. Istovremeno su oni najrevnosniji korisnici Interneta. Stoga je analiza komentara na tekstove o siromaštu trebalo da da odgovor na pitanje da li internetski korisnici medijskih sadržaja reaguju na ovakav način medijske prezentacije siromaštva.

Pokazalo se da su veoma aktivni u sajber prostorvremenu i pošto su i sami subjekt istraživane teme otvaraju javnu polemiku o pitanjima o kojima mediji ne pokreću javni dijalog. Za razliku od diskursa moći, kojima su markirani medijski tekstovi, komentari su pokazali da u Srbiji ,žive” siromašni koji su spremni da u virtuelnoj zajednici participiraju u kreiranju javnog mnjenja o jednom od najvećih problema današnje Srbije - siromaštvu.

Grajsov princip kooperativnosti su u potpunosti poštovali novinari u javnoj komunikaciji, a većinu kategorija ovog principa internetski korisnici u komentarima nisu prepoznali kao značajne za održavanje interaktivnosti. Ovaj nalaz se može smatrati i očekivanim pošto je Internet markiran kao otvorena, uglavnom bez jasnih, univerzalno važećih ograničenja, stega i pravila ponašanja virtuelna prostor-vremezajednica.

Ono što je u ovom tekstu na žalost izostalo, zbog ograničenog prostora, jeste analiza potpisa autora komentara koji su najčešće pseudonim i predstavljaju „komentar na komentar”, tačnije dodatnu „podršku” komentaru.

\section{LITERATURA}

Grice, P. H. (1975/1967/). Logic and Conversation. Syntax \& Semantics. Vol 3, Cole i Morgan T.L. ed., Academic Press, 41-58.

Grice, P. H. (1987). Logika i razgovor, Kontekst i značenje. Miščević, N. i Matjaž, P. ur. Rijeka : Izdavački centar Rijeka. 
Konačna analiza - Internet marketing u Srbiji i Hrvatskoj (2011)

http://www.hugemedia.rs/blog/2011/07/29/konacna-analiza-internetmarketing-u-srbiji-i-hrvatskoj/, pregledano 23.05.2012.

Levinson, C. S. (1983). Pragmatics. Cambridge Textbook in Linguistics. Cambridge : Cambridge University press.

Ministarstvo mladih ne sme biti ukinuto (1. 05.2012). YOUTH.RS. http:// youth.rs/njuz/ministarstvo-omladine-ne-sme-biti-ukinuto, pregledano 27.05.2012.

http://youth.rs/njuz/ministarstvo-omladine-ne-sme-biti-ukinuto

Leech, G. (1989 /1983/). The Principles of Pragmatics, Sixth Impression. London-New York : Longman, Linguistics Library.

Valić Nedeljković, D. (1997). Radijski intervju. Beograd : Zadužbina Andrejević.

Valić Nedeljković, D. ur. (2011). Media discourse of poverty and social exclusion. Novi Sad : Filozofski fakultet.

van Dijk, T. A. (1985). Semantička analiza diskursa. Revija, časopis za književnost, kulturu i društvena pitanja, br. 5-6, Osijek, 13-27.

van Dijk, T. A. (1995). What is political discourse analysis, rad izložen na Godišnjoj konferenciji Belgijskog lingvističkog udruženja: Political linguistic, 7-9. Decembar 1995, Antverpen.

van Dijk Teun Adrianus (2008). Discourse and Power. Houndmills, Basingstoke, Hampshire: Palgrave Macmillan.

Verschueren, J. (1995a). The pragmatic perspective, Handbook of Pragmatics, ed. Verschueren,J, Ostman, J. O, Blommaert, J. Amsterdam/Philadelphia : Ofprint, str. 1-17.

Vershueren, J. (1995b). Linguistic pragmatics and semiotics. Semiotica 1041/2. Berlin*New York : Mouton de Gruyter, str. 45-65.

Vučković, P. (1995). Ogledi iz semantike i pragmatike. Beograd : Savremena administracija.

Dubravka Valić Nedeljković

INTERNET MEDIA PRESENTATION OF POVERTY FROM THE PERSPECTIVE OF GRICE'S PRINCIPLE OF COOPERATION AND LEECH'S PRICIPLE OF POLITENESS 


\section{Summary}

This paper presents the results of the analysis of texts and comments on the texts about poverty and social exclusion on the on-line edition B92 from the perspective of Grice's principle of cooperation and Leech's principle of politeness.

The special attention was put on a review of units of analysis.

The unit of analysis is conversational - comprised of communicative acts: journalists' text and comments of the users of B92.net web site.

The aim is to observe communication between text and comments, as well as between comments themselves, in relation to the lexical choices that (do not) satisfy the principle of cooperation and principle of politeness, and more precisely their categories and maxims.

The analysis showed that categories and maxims of Grice's principle cooperation proved to be very applicable in the analyzed corpus and that they can be used in the analysis of media content. At the same time, although the observed corpus includes the interaction on the Internet, Leech's principles of politeness have not been proven applicable to a given corpus.

Keywords: Internet, principle of cooperation, politeness principle, maxim, categories, media text, comments 